\title{
LA PRIMERA GUERRA MUNDIAL, CRISIS ECONÓMICA Y AGUDIZACIÓN DEL CONFLICTO OBRERO EN ARGENTINA
}

\author{
A Primeira Guerra Mundial, crise econômica e \\ agravamento do conflito trabalhista na Argentina \\ World War I, economic crisis and aggravation \\ of labor conflict in Argentina
}

JUAN SURIANO

http://dx.doi.org/10.1590/\$2178-14942017000100006

\footnotetext{
Juan Suriano é mestre em História pelo Instituto Superior de Estudos Sociais da Universidade Nacional de San Martín (Argentina), professor de História dessa instituiçãa, e doutor em História pela Faculdade de Filosofia e Letras da Universidade de Buenos Aires. (juansuriano03@gmail.com).

Artigo recebido em 1 de dezembro de 2016 e aprovado para publicação em 2 de fevereiro de 2017.

Revisión del texto en español de Óscar Curros.
} 


\section{RESUMEN}

Este artículo analiza, a partir del impacto provocado por la Primera Guerra Mundial en la economía argentina, las consecuencias en el movimiento obrero: la desocupación, la caída de los salarios y el deterioro en las condiciones de trabajo. Esta situación negativa terminó incentivando y radicalizando el conflicto social de manera inédita, especialmente en aquellos gremios vinculados a las exportaciones (marítimos, ferroviarios, obreros de la industria frigorífica). Así, un evento excepcional, la guerra, desnudó en todas sus dimensiones las formas de interpenetración e interconexión que había adquirido la economía mundial y las formas en que esta situación incidía sobre el conjunto de los trabajadores.

Palabras-Clave: Primera Guerra Mundial, desocupación, sindicatos, huelga.

\section{RESUMO}

Este artigo analisa, a partir do impacto causado pela Primeira Guerra Mundial na economia da Argentina, as consequências no movimento operário: o desemprego, a queda dos salários e a deterioração das condições de trabalho. Essa situação negativa terminou incentivando e radicalizando o conflito social de uma forma inédita, especialmente nos sindicatos ligados à exportação (marítimos, ferroviários, de trabalhadores na indústria frigorífica). Assim, um acontecimento excepcional como a guerra mostrou em todas as suas dimensões as formas de interpenetração e interligação que a economia global tinha adquirido e as formas como essa situação afetou a toda a força de trabalho.

Palavras-Chave: Primeira Guerra Mundial, desemprego, sindicatos, greve.

\section{AbSTRACT}

This article analyzes, considering the impact of First World War on Argentine economy, the consequences on the labor movement: unemployment, falling wages and deterioration of working conditions. This negative situation encouraged and radicalized the social conflict in an unprecedented way, especially in those unions related to exportation (maritime, railway, refrigeration industry workers). Thus, an exceptional event such as the war stripped in all its dimensions the forms of interpenetration and interconnection that the world economy had acquired and the ways in which this situation affected all workers.

KeYwORDs: World War I, unemployment, unions, strike. 


\begin{abstract}
A los trabajadores y al pueblo en general.
La actual situación nos obliga seriamente de la suerte dolorosa que les está reservada a los trabajadores de aquella parte del mundo, envuelta en la más pavorosa de las tragedias que registran las páginas de sangre de la historia de las guerras. Y tenemos que preocuparnos seriamente porque, en primer lugar, la clase obrera, el proletariado en su totalidad es el arrastrado al sacrificio para defender o conquistar intereses de la burguesía; de la clase criminal que tiene en sus manos el Estado con todas sus fuerzas $y$, que espera con la guerra realizar un buen negocio. Los trabajadores argentinos, sin distinción de nacionalidades ni de ninguna índole, sabrán lanzar un formidable anatema contra todos los causantes de la guerra... Los trabajadores no queremos patria ni banderas y todos los trabajadores del mundo no tenemos más que un enemigo: "la sociedad burguesa".
\end{abstract}

Trabajadores: contra la guerra, contra la burguesía, la revolución social.

Manifiesto del Consejo Federal de la FORA, agosto de 1914 (Santillán, 1971: 221-223)

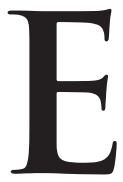

$s$ muy difícil comprender los efectos económicos, políticos y sociales que la

Primera Guerra Mundial tuvo en nuestro país sin tener en claro la magnitud de semejante conflagración. Se trató de un evento inédito en la historia mundial y, dada la impresionante cantidad de víctimas que provocó, ${ }^{1}$ no resulta exagerada la afirmación que Eric Hobsbawm tomó del historiador David Singer, quien sostuvo que en 1914 comenzó la "era de las matanzas". Visto en perspectiva histórica, ningún conflicto armado entre naciones, reinos o imperios alcanzó tal magnitud, "participaron todas las grandes potencias y todos los Estados europeos, excepto España, los Países Bajos, los tres países escandinavos y Suiza. Además, diversos países de ultramar enviaron tropas, en muchos casos por primera vez, a luchar fuera de su región... Los Estados Unidos desatendieron la advertencia de George Washington de no dejarse involucrar en los 'problemas europeos' y trasladaron sus ejércitos a Europa, condicionando con esa decisión la trayectoria histórica del siglo XX. Los indios fueron enviados a Europa y el Próximo Oriente, batallones de trabajo chinos viajaron a Occidente y hubo africanos que sirvieron en el ejército francés" (Hobsbawm, 1995: 31; Stevenson, 2013). 
El Gobierno argentino, tanto durante el mandato del presidente Victorino de la Plaza, en 1914, como durante el de su sucesor, Hipólito Yrigoyen, en 1916, declaró y mantuvo la neutralidad. Pero se vio sometido a enormes presiones de las naciones aliadas, las grandes empresas de esos países que operaban aquí y una parte de la opinión pública para que tomara partido y declarara la guerra a Alemania, aunque también había sectores minoritarios vinculados a los intereses germanos que respaldaban la neutralidad de nuestro país.

Si las guerras anteriores se habían producido por motivos limitados y concretos, la que estalló en 1914, según Hobsbawm, parecía perseguir objetivos ilimitados. "En la era imperialista, se había producido la fusión de la política y la economía. La rivalidad política internacional se establecía en función del crecimiento y la competitividad de la economía, pero el rasgo característico era que no tenía límites". Las fronteras naturales de las grandes empresas alemanas, inglesas o francesas no tenían ni toleraban límites a su capacidad de expansión. Dado que durante los primeros años de la guerra ninguno de los bandos podía establecer una superioridad y vencer al otro, las dos partes en conflicto trataron de bloquear la llegada de alimentos y productos básicos a los países enemigos con el objeto de desmoralizar a las poblaciones civiles. Los alemanes implementaron la guerra submarina, con la meta clara de aislar a Gran Bretaña, y este hecho provocó la entrada de Estados Unidos en la contienda. A la vez, los británicos usaron todos sus medios y recursos para impedir el envío de suministros a Alemania, con el objeto de ahogar su economía de guerra y provocar hambre entre su población (Hobsbawm, 1995: 3-38). En mayor o menor medida todas las economías del mundo, incluso aquellas más alejadas, que no participaban directamente en la guerra, se vieron afectadas por este largo y cruento conflicto.

Porque, si la Gran Guerra había desestructurado de manera brutal la economía y la sociedad europeas, el impacto en estas tierras (y en el resto de Latinoamérica) fue, por supuesto, de otra magnitud, pero también muy importante, pues afectó los diversos niveles de la actividad económica, así como las esferas social, cultural y política. No podría haber sido de otra manera. Aunque los combates y las matanzas se producían lejos, desde hacía varias décadas la economía argentina estaba fuertemente imbricada con el mercado internacional, del cual dependía. El comercio exterior, las exportaciones de productos primarios y las importaciones dependían de la relación con los países centrales. Además, buena parte de los empresarios y trabajadores también provenían de Europa y muchos no pudieron dejar de involucrarse emocional o ideológicamente (el llamado de la patria) en la contienda; no fueron pocos los inmigrantes que partieron y se alistaron en los ejércitos de sus naciones. La política también fue condicionada por la postura adoptada frente a los bandos: el Gobierno, porque declaró la neutralidad; las fracciones políticas mayoritarias (rupturistas), que lo presionaban 
para apoyar a los aliados y romper relaciones con Alemania; y algunos sectores minoritarios, que influían para mantener la neutralidad. Por su parte, los sectores de la izquierda argentina (socialismo y anarquismo) tampoco pudieron evitar manifestar posturas enfrentadas frente a la guerra. Esas divisiones políticas se trasladaron también al ámbito cultural e intelectual, en donde predominaban las miradas a favor de los aliados (Compagnon, 2013).

\section{EL IMPACTO DE LA GUERRA EN EL MUNDO DEL TRABAJO}

A diferencia de la Segunda Guerra Mundial, que mereció la atención de la historiografía y prácticas culturales, sociales y políticas asociadas a la Segunda Guerra ya estaban presentes entre 1914 y 1918" (Tato, 2014: 92). Cabe aclarar que es este un rasgo común de la historiografía latinoamericana (Compagnon, 2009: 31-43). La mayoría de los trabajos que se han referido a la Gran Guerra en Argentina se concentraron especialmente en la economía y en los vínculos diplomáticos del país con los países beligerantes. En este último sentido se ha prestado atención a la firme postura neutralista del Gobierno argentino, más allá de las fuertes presiones de Gran Bretaña y del panamericanismo impulsado por Estados Unidos. En los últimos años ha comenzado a prestarse atención al rol desempeñado por la opinión pública durante el conflicto y se ha puesto énfasis en las afinidades culturales e ideológicas de diversos actores sociales locales, especialmente los inmigrantes, con los países involucrados en la guerra. Estos trabajos han revelado un fuerte compromiso de las diversas comunidades étnicas presentes en el país con sus naciones de origen, despertando las tendencias nacionalistas y creando una fuerte polarización entre aliadófilos (rupturistas) y neutralistas (Compagnon, 2007: 7791; Tato, 2014: 91-101). No obstante estos aires renovadores de la historiografía argentina, reforzados en ocasión de cumplirse, en 2014, el centenario del comienzo de la Gran Guerra, aún existe un enorme vacío en relación con el impacto político, ideológico y cultural de la conflagración sobre la clase obrera. Este vacío se vincula al escaso interés de los historiadores del mundo del trabajo local por relacionar este con el contexto internacional.

El mundo del trabajo argentino (tanto las empresas como, particularmente, el conjunto los trabajadores) se vería gravemente afectado durante los años que duró la guerra. ${ }^{2}$ Ya poco antes del conflicto se percibían signos evidentes de desaceleración de la economía argentina. Cuando comenzó la guerra, en agosto de 1914, el país arrastraba el fracaso de la cosecha de granos del año anterior y la disminución de la entrada de capitales extranjeros debido a las restricciones monetarias impuestas por Europa, así como por el reembolso de intereses y amortizaciones de sus capitales en nuestro país y en el resto de Latinoamérica. ${ }^{3}$ Hacia 1914 
el PBI cayó un 10\%; la inversión externa, un 30\%; y la baja del comercio exterior superaba un 20\%. Los gremialistas de la Confederación Obrera de la República Argentina (CORA) percibieron rápidamente los efectos negativos de esta situación y advertían: "La actual crisis económica, la desocupación... Benefician enormemente la explotación capitalista, colocando a la clase obrera en una situación desventajosa y en vías de perder una a una las mejoras alcanzadas". ${ }^{4}$

En este contexto negativo, el estallido de la guerra agudizó profundamente la crisis de la economía argentina, al incentivar la salida de las reservas de oro, con la consecuente reducción del capital circulante, el cese de la inversión extranjera y la pérdida de la capacidad de embarque, así como la caída de las exportaciones de grano y las importaciones, que en 1918 representaron la mitad de las de 1910. No obstante, la balanza comercial se recuperó con cierta rapidez debido a la fuerte demanda de carnes congeladas por parte de Gran Bretaña y por la mencionada caída espectacular de las importaciones. Pero los precios de los artículos importados aumentaron más que los de exportación, lo que empeoró los términos de intercambio para nuestro país. Además, consecuentemente se redujeron de manera sustancial los niveles de recaudación de las arcas fiscales, debido a la caída de los gravámenes provenientes del comercio exterior.

Si bien es cierto que en pocos años la caída de las importaciones encaminaría un relativo proceso de sustitución de productos industriales (alimentación, metalurgia liviana, vestido), lo que a su vez provocaría un crecimiento moderado de la industria nacional y una mayor participación de esta en el producto bruto, durante la guerra la pronunciada caída de las importaciones de insumos provenientes principalmente de Gran Bretaña, como el carbón de piedra, los combustibles, las maquinarias y equipos, afectó de manera ostensible a algunas ramas de la industria argentina, especialmente la metalurgia, que dependía de la afluencia de dichos insumos. Entre los años 1913 y 1918 la importación de combustibles se redujo un $60 \%$, los artefactos de hierro y otros metales la mitad, mientras que la entrada de maquinarias y vehículos cayó en torno a un 80\% (Dorfman, 1970: 324). Lógicamente esta coyuntura contribuyó a que el PBI se contrajera a un ritmo del 8,1 \% anual entre 1913 y 1917 (Belini y Korol, 2012: 26).

Esta situación tuvo una fuerte incidencia sobre los niveles de ocupación de la mano de obra, que cayó ostensiblemente durante los primeros años de la conflagración. Los obreros ocupados en la industria disminuyeron de 344.000, en 1914, a 292.000, en 1917. Alejandro Bunge había calculado un año antes que el porcentaje de desocupación era del 23,8\% en la Capital Federal y del $16,4 \%$ en el resto del país. Esta situación afectaba en mayor o menor medida todo el territorio nacional (Bunge, 1917). La paralización de la obra pública, la caída 
del empleo en el sector estatal, en la construcción privada (especialmente en el ferrocarril) y la quiebra de empresas provocaron una desocupación cercana a un 20\%. Una cifra alta, si se tiene en cuenta que el desempleo se vio morigerado por el abrupto descenso de la inmigración. Si en los cuatro años previos a la Primera Guerra Mundial (1909-1913) se había producido un saldo favorable de 802.000 inmigrantes, durante la misma cantidad de años que duró la conflagración (1914-1918) el saldo negativo ascendió a 92.000 personas (Lobato y Suriano, 2000: 571$).^{5}$

El congelamiento de los salarios y el fuerte aumento de los precios de los artículos de consumo ocasionaron una pronunciada caída del salario real, especialmente durante el período final de la guerra. Los precios de los alimentos subieron en torno a un $50 \%$ entre 1914 y 1918, en parte como consecuencia de la creciente demanda externa de los insumos agropecuarios, cuya oferta inelástica encarecía dichos productos en el mercado interno. En tanto, también subieron los alquileres alrededor de un 15\% y la vestimenta aumentó en torno a un 300\%. La mayoría de los informes elaborados sobre esta cuestión son claramente negativos. Si tomamos los datos suministrados por el informe Investigaciones Sociales del Departamento Nacional del Trabajo correspondiente a los años 1938-1940, la evolución del costo de vida (base: octubre de 1933: 100) fue de 92,4 en 1913, para llegar a 156,5 en 1918 (DORFMAN, 1970: 270). Si nos basamos, en cambio, en la elaboración más sofisticada de los datos económicos durante estos años, realizada por Guido Di Tella y Manuel Zimelman, las cifras son ligeramente diferentes, pero de similar magnitud.

\section{CUADRO № 1}

Nivel de ocupación, ingresos y producción industrial, 1914-1920

\begin{tabular}{|c|c|c|c|c|}
\hline & $\begin{array}{c}\% \\
\text { Desocupados }\end{array}$ & $\begin{array}{l}\text { Costo de vida } \\
(1910=100)\end{array}$ & $\begin{array}{l}\text { Salarios reales } \\
(1929=100)\end{array}$ & $\begin{array}{l}\text { Volumen Prod. Ind. } \\
\qquad(1950=100)\end{array}$ \\
\hline 1914 & 13,4 & 108 & - & 20,3 \\
\hline 1915 & 14,5 & 117 & 61 & 18,2 \\
\hline 1916 & 17,7 & 125 & 57 & 18,7 \\
\hline 1917 & 19,4 & 146 & 49 & 18,5 \\
\hline 1918 & 12,0 & 173 & 42 & 22,1 \\
\hline 1919 & 7,9 & 186 & 57 & 23,0 \\
\hline 1920 & 7,2 & 171 & 84 & 23,8 \\
\hline
\end{tabular}

Fuente: (Di Tella y Zymelman, 1967: 309, 317, 339 y 343)

Esta situación incidió directamente sobre los salarios reales, que, como sugiere el cuadro anterior, descendieron aproximadamente un 30\% durante los cuatro años de conflagración. La pérdida de poder adquisitivo de los trabajadores parecía revertir, al menos 
coyunturalmente, la tendencia de altos salarios percibidos en la Argentina en relación con los propios países industrializados durante la década anterior. Alejandro Bunge, entonces director de la División de Estadísticas del Departamento Nacional del Trabajo, sostenía que en plena Guerra Mundial "de nuestra investigación resulta que los salarios mensuales nominales, en Buenos Aires, son del $66 \%$ más elevados que en las grandes ciudades inglesas, pero el salario real es inferior en un 9\%". ${ }^{6}$ El mismo Bunge calculaba que, teniendo en cuenta la inflación provocada por la guerra, los salarios nominales deberían haberse elevado en 1918 a 160 pesos, sin embargo oscilaban alrededor de los 100 pesos mensuales. David Rock sostiene que esta situación negativa para la clase trabajadora "ilustra hasta qué punto la guerra tuvo como corolario redistribuir el ingreso restándolo a la clase obrera, así como las presiones que alentaron las huelgas... [que]... afectaron principalmente los sectores de la economía controlados por el capital extranjero, con especial incidencia en aquellas áreas que dependían de una oferta irregular y onerosa de materias primas y combustibles importados" (Rock, 1977: 139).

Sin duda, a partir de 1913, las condiciones de vida y de trabajo de la clase obrera argentina comenzaron a deteriorarse seriamente, para agudizarse con el estallido de la guerra. Durante los primeros años los altos niveles de desocupación desalentaron la protesta obrera. No obstante, los sindicatos alertaban constantemente sobre el aumento de la desocupación y el deterioro salarial. Los dirigentes sindicales, que veían cómo la cantidad de cotizantes a los gremios descendía día tras día, eran conscientes de la debilidad que atravesaban las organizaciones en esta difícil coyuntura para movilizar a los trabajadores, en un momento en que cualquiera de ellos podía perder su puesto de trabajo. Por esta razón, la protesta se centró y se limitó a la elaboración de diversas propuestas destinadas a moderar los efectos de la desocupación y la caída del salario. La CORA planteó sin éxito como posible solución al problema la implementación por parte del Gobierno de la reducción de la jornada laboral. En esta línea el Sindicato de Ebanistas primero, la Federación Gráfica Bonaerense después, propusieron adoptar la semana inglesa de 44 horas de trabajo. Esta misma organización implementó un subsidio para los desocupados de la industria gráfica y elevó la cuota en 20 centavos mensuales a sus afiliados con el objeto de acrecentar el fondo creado a tal fin. "Además ha impuesto la jornada de 7 horas" (Marotta, 1961: 147). Como consecuencia del malestar existente por esta situación, el 11 de octubre de 1914 se realizó en Plaza Constitución una manifestación contra la carestía y la desocupación, en la que participaron varias columnas integradas por trabajadores de diversos gremios, organizadas territorialmente en los barrios de mayor concentración obrera, como Barracas, Parque de los Patricios, Belgrano, Villa Crespo, Flores y Once. 


\section{LA RECOMPOSICIÓN DEL MOVIMIENTO OBRERO}

$\mathrm{E}$ stas protestas no alcanzaron dimensiones importantes y se fueron diluyendo, predominando durante la primera mitad de la guerra un bajo nivel de movilización, la pérdida de cotizantes en los sindicatos y una marcada debilidad de la protesta obrera. Veinte años después el dirigente anarquista Abad de Santillán se hizo eco de este clima, al plantear que esos años fueron "de calma y espera. No es que en ese período no haya habido huelgas numerosas, boicots intensos y tenaces manifestaciones públicas diversas de la actividad gremial; pero el mundo vivía pendiente de la terminación de la guerra y sufría la consecuencia de la larga ruptura de las relaciones internacionales" (Santillan, 1971: 241). No solo la crisis desalentaba la movilización obrera, también incidía la fuerte división que recorría al gremialismo argentino y que tuvo su punto culminante en 1915 en el IX Congreso de la Federación Obrera Regional Argentina (FORA), cuando los gremios orientados por dirigentes anarquistas se retiraron al quedar en minoría frente a los representantes del sindicalismo revolucionario y conformaron su propia organización, denominada FORA del V Congreso. Por su parte, el socialismo local arrastraba desde hacía años un duro enfrentamiento entre su conducción política y el ala gremial. Aunque estos datos no son novedosos, pues las divisiones existieron desde el mismo origen del gremialismo argentino, como ocurría por otra parte con el movimiento obrero de otras latitudes, la falta de unidad en épocas de crisis afectaba aún más la organización unificada de la protesta.

Pero esa calma se quebraría desde fines de 1916 y comienzos de 1917, en cuanto comenzaron a evidenciarse algunos atisbos de la recuperación de la economía, especialmente en el año1918, con la reactivación de la producción industrial y una mayor demanda de brazos, que provocó una caída de siete puntos en el desempleo. Este mejoramiento no se trasladó a los salarios reales, que siguieron disminuyendo debido al aumento del costo de vida. (Véase el Cuadro № 1). Los trabajadores comenzaron a desarrollar un ciclo de protestas como nunca antes se habían producido en la joven historia del movimiento obrero local, que se prolongaría hasta 1921. Ese período de cinco años de conflicto sindical ha sido denominado por la historiografía el Quinquenio Revolucionario, incluidos los sucesos de la Semana Trágica, uno de los conflictos obreros (junto al Cordobazo de 1969 y la jornada del 17 de octubre de 1945) más importantes que se produjeron durante el siglo XX en Argentina. El aumento de la conflictividad obrera provocó un notable crecimiento de la afiliación sindical en la FORA del IX Congreso (de orientación sindicalista), que pasó de 20 gremios adheridos y 21.000 afiliados cotizantes por año en 1915 (2.600 afiliados mensuales) a 734 gremios y 749.000 cotizantes (68.000 afiliados mensuales) en 1920 (Bilsky, 1984: 24). Por otro lado, 
esta organización creó las primeras federaciones por industria, entre las cuales resaltaron sin duda la Federación Obrera Marítima (FOM) y la Federación Obrera Ferrocarrilera (FOF); incorporó a federaciones locales, como la rosarina, antes dirigida por el anarquismo, organizó a conjuntos de trabajadores que no tenían representación gremial de la administración pública (Correos y Telégrafos, municipales u hospitales) y extendió la acción gremial fuera del área del litoral, con lo que alcanzó hasta a los trabajadores de los quebrachales y de la Patagonia.

CUADRO № 2

Resumen general de huelgas en la Capital Federal, 1913-1920

\begin{tabular}{|c|c|c|c|}
\hline Años & № Huelgas & № Huelguistas & Jornadas perdidas \\
\hline 1913 & 95 & 23.698 & 147.651 \\
\hline 1914 & 64 & 14.137 & 83.044 \\
\hline 1915 & 65 & 12.077 & 49.183 \\
\hline 1916 & 80 & 24.321 & 233.878 \\
\hline 1917 & 138 & 136.062 & 2.100 .269 \\
\hline 1918 & 196 & 133.042 & 2.191 .773 \\
\hline 1919 & 367 & 308.961 & 3.262 .705 \\
\hline 1920 & 206 & 134.015 & 3.693 .782 \\
\hline
\end{tabular}

Fuente: Mirta Zaida Lobato y Juan Suriano, "Argentina 1880-1930: huelgas generales en un país agroexportador". En: Latín Americal Labor New/s, № 2/3, 1990, p.19.

Estas cifras de huelgas, recopiladas por el Departamento Nacional del Trabajo, se refieren tan solo a la Capital Federal, por lo que quedan fuera de este cuadro importantes sectores de los obreros, especialmente la mayoría de ferroviarios y una parte de los marítimos, que operaban fuera de la ciudad, así como también los trabajadores de la carne de los grandes frigoríficos asentados en Avellaneda, Berisso, Ensenada y Zárate, en la provincia de Buenos Aires. No obstante, estos datos son significativos de la magnitud del conflicto obrero a partir de 1917, comparados a los años previos. En ese año y el siguiente más de la mitad de los trabajadores que hicieron huelga eran ferroviarios, el resto se repartían entre los gremios de carreros, choferes, estibadores, metalúrgicos, marítimos, municipales, ladrilleros, zapateros y otros. ${ }^{7}$ Las causas de un $40 \%$ de las huelgas se debían a reclamos de recomposición salarial, un $32 \%$, a demandas vinculadas a efectivizar el derecho de organización sindical y el resto se produjo por reclamos de reducción de las horas de trabajo y de la mejora de las condiciones de trabajo. ${ }^{8}$

Si la crisis provocada por la guerra había desalentado la conflictividad obrera, desde fines de 1916, con el lento inicio de la recuperación económica, los gremios comenzaron 
a multiplicar sus reclamos y trataron de capitalizar el fuerte malestar de los trabajadores, acumulado durante los años de deterioro de sus niveles de vida. La fuerte dependencia que tenía la economía argentina del mercado internacional arrastraba, como se ha dicho, a sus diversos sectores productivos según las necesidades (demandas) de los países aliados. Esto ocurría especialmente con la industria de la carne, cuyos trabajadores realizarían importantes huelgas. Aunque debe resaltarse que el protagonismo del ciclo de conflictos que se iniciaba estaba vinculado a los reclamos y las huelgas de los dos principales gremios de la economía argentina: la Federación Obrera Marítima y la Federación Obrera Ferrocarrilera. La capacidad de presión de estos gremios se debía, especialmente el primero, a la fortaleza organizativa y al lugar central que ocupaban en el sistema de transporte involucrado en el comercio exterior, del que eran la columna vertebral. Las huelgas en este sector perturbarían seriamente la ya deteriorada economía argentina y, en consecuencia, eran un tema de interés estratégico del Gobierno. Si bien no fueron los únicos, me centraré aquí en los conflictos acaecidos en el transporte marítimo y ferroviario, así como en la industria de la carne, pues los tres sectores eran los principales puntales de la economía agroexportadora y su marcha se vinculaba estrechamente a la situación internacional.

Durante los primeros años del conflicto bélico, la industria frigorífica, en sentido contrario al resto de la actividad productiva, se vio beneficiada debido a la impresionante demanda de alimentos derivados de la carne para el abastecimiento de los ejércitos aliados, puesto que los grandes establecimientos cárnicos de la Argentina (Swift, Anglo y Smithfield) eran de capitales norteamericanos o ingleses. Por ejemplo, "El Swift [radicado en Berisso] entró en un clima febril de trabajo al producir carnes enlatadas para el abastecimiento de los países beligerantes. Desde 1914 aumentó la faena de ganado para exportación y la matanza de vacunos se incrementó hasta duplicar los valores existentes al comenzar la guerra" (Lobato, 2001: 159). Con el objeto de aumentar la producción, las empresas frigoríficas intensificaron, como hacían cada vez que aumentaba la demanda, los ritmos de trabajo, empeorando así las ya deficientes condiciones labora les de los trabajadores. El diario El Día, de La Plata, denunciaba que "la administración del frigorífico se ha abusado hasta el más increíble punto con los trabajadores... Con distintos pretextos ha exigido al personal que trabaje 10, $14 \mathrm{y}$ hasta 16 horas diarias, luego por las exigencias de la guerra europea ha hecho trabajar a las mujeres del departamento de conservas sin descanso". ${ }^{9}$ Esta situación se reiteraba, en mayor o menor medida, en el resto de los frigoríficos. A pesar de la situación favorable, las empresas no mejoraron los salarios ni aceptaron pagar las horas excedentes de la jornadas de ocho horas como extras, por lo que se produjo una interesante paradoja: mientras las empresas se veían altamente beneficiadas por la coyuntura, los trabajadores de la carne se encontraron 
en las mismas condiciones que el resto de los obreros de otros rubros que, a diferencia de la industria cárnica, se hallaban perjudicados por la crisis.

Las características del trabajo en estas industrias (descalificación laboral, inestabilidad, alta rotación en el empleo, represión, diversidad étnica y capacidad de la empresa para contratar y despedir trabajadores sin ningún costo) conspiraban contra las posibilidades de articular una sólida organización sindical. No obstante, en esta coyuntura favorable de aumento de la producción y de demanda de mano de obra, los trabajadores percibieron que era el momento de protestar y presionar a las empresas. A mediados de 1915, en el contexto de un proceso incipiente de agremiación, declararon la huelga, para reclamar mejores condiciones laborales, aumento de los salarios, la jornada laboral de ocho horas y el pago de un 50 por ciento más sobre las horas extras; pero, además, exigían que la provisión de trabajadores estuviera a cargo del sindicato, hecho que implicaba el control del ingreso de la mano de obra a la empresa. La coyuntura de la guerra obligó en un principio a las empresas frigoríficas a negociar algunas de las demandas, aceptando aparentemente la implementación de la jornada de ocho horas diarias más los pagos extras sin tomar represalias. Sin embargo, acostumbradas a imponer sus condiciones de trabajo, no tenían intenciones de ceder a las demandas y la negociación solo pretendía hacerles ganar el tiempo necesario para contratar rompehuelgas, con el objeto de normalizar la producción. Cuando estos llegaron a Berisso, suspendieron las conversaciones con los representantes obreros y, 40 días después de comenzada la huelga, los trabajadores no tuvieron más remedio que aceptar la derrota y soportar el despido de los participantes más activos y la cárcel de algunos dirigentes.

En 1917 el malestar y la agitación obrera por la persistencia de las pésimas condiciones de trabajo se extendieron a los frigoríficos más importantes (Swift y Armour, de Berisso; Hall y Smithfield, de Zárate) y desembocó en una de las huelgas más importantes en la historia de esta industria, en demanda de los mismos reclamos del conflicto anterior: jornada máxima de 8 horas, jornal doble los domingos, aumento salarial de un 15 por ciento, mejoras en las condiciones de trabajo y la readmisión de los obreros despedidos en el conflicto de 1915. Pero, en esta ocasión, el conflicto se desarrolló en circunstancias negativas para los frigoríficos, puesto que "la intensificación de la guerra submarina y la escasez de vapores obligaban a reducir notablemente la producción" y, por ende, a incrementar los despidos y achicar el personal contratado eventualmente. No obstante, en esta ocasión, los obreros de la carne estaban mejor organizados e intentaban evitar la fragmentación predominante durante el conflicto anterior. Se implementaron piquetes de huelguistas para impedir la entrada de los trabajadores más refractarios a la huelga y de los esquiroles contratados por la empresa. Tras dos meses de intenso conflicto, con picos de inusitada violencia como consecuencia de la 
represión policial y con el saldo de numerosos heridos y detenidos, la huelga se diluyó, con una nueva derrota de los trabajadores, de la que no se recuperarían por largo tiempo (Lobato, 2001:165-180).

En el sector marítimo la crisis producida por la guerra también repercutió en la actividad naval y se hizo visible tanto en la menor cantidad de amarres como en el número de partidas de buques. Esta situación se reflejó directamente en las estrategias adoptadas por los empresarios navieros para paliar la situación, recurriendo a la reducción salarial (ya en 1914 había descendido un 10\%) y de personal (en agosto de 1914 cerraron los talleres de la empresa Mihanovich en las localidades de Salto y Carmelo, en Uruguay). No obstante las dificultades, el gremio logró mantener su actividad y reforzar algunos aspectos de su organización, con el objeto de preservar el sindicato. Los reclamos defensivos estaban dirigidos a la Prefectura Naval, en busca del cumplimiento de las leyes y reglamentos que regían la actividad (horarios de labor a bordo y tripulación mínima) y al DNT, exigiendo una minuciosa inspección de los buques para preservar las condiciones de trabajo. A medida que avanzaba la guerra y la actividad naviera se resentía, se profundizaba el malestar de los trabajadores marítimos, por dos motivos centrales: por un lado, la caída del salario (real y nominal) era un hecho que repercutió directamente en las condiciones de vida de los trabajadores navales; por otro, también empeoraron las condiciones de trabajo a bordo,por la disminución del personal, lo que provocaba la prolongación de los turnos laborales y la intensificación del trabajo (Caruso, 2016: 133-183).

Pero, en este caso, a diferencia de la débil organización que caracterizaba a los obreros de la carne, los marítimos estaban mejor organizados y, desde 1910, se nucleaban en torno a la Federación Obrera Marítima, orientada por el sindicalismo revolucionario. Sus reclamos excedían las reivindicaciones económicas, como el aumento salarial o las condiciones de trabajo, para avanzar en la exigencia del control sindical del ingreso al trabajo. Sus dirigentes demostraron, además, pragmatismo y capacidad de negociación; así, frente a la arbitrariedad de los empresarios navieros, buscaron el amparo del gobierno de Yrigoyen, quien, proclive a mediar en los conflictos obreros patronales, en varias ocasiones laudó favorablemente al sindicato. Entre 1916 y 1920 los navales realizaron varios paros parciales y un par de huelgas generales, con el apoyo masivo de todo el personal de cubierta (desde los capitanes hasta los trabajadores de menor calificación), uno de los grandes logros de la Federación. El conflicto tuvo la capacidad de paralizar el comercio exterior.

El ciclo huelguístico comenzó el 1o de diciembre de 1916, al declararse la huelga general en el puerto de Buenos Aires, ante la negativa patronal a los reclamos de recuperación salarial y de mejora de las condiciones laborales. El paro fue masivo y paralizó totalmente 
la actividad portuaria, con el apoyo de los estibadores y los patrones de lanchas del puerto porteño, quienes se negaron a trabajar con barcos que emplearan tripulantes no afiliados a la FOM. En esta ocasión contaron con el apoyo del gobierno de Yrigoyen, que decidió retirar a la Prefectura Naval, permitiendo así que los piquetes de obreros controlaran el movimiento dentro del puerto. Aunque al comienzo las grandes empresas encabezadas por Mihanovich se negaron a negociar, finalmente cedieron, con la condición de que se eliminaran algunos impuestos y de que el presidente fuera el garante de la mediación. El mayor éxito de la FOM fue lograr la contratación exclusiva de obreros sindicalizados para trabajar a bordo de las embarcaciones de bandera argentina. Este fue el punto de mayor fricción entre las empresas y la FOM, que desembocó en los tres años siguientes en varias huelgas masivas de los trabajadores marítimos, quienes lograron conservar el poder de contratación. En 1921, en una coyuntura de debilidad sindical, las grandes empresas lograron que el mismo Yrigoyen suprimiera esta cláusula y devolviera a la Prefectura el control del puerto. Cinco años había durado una de las experiencias del movimiento obrero que mayor poder otorgó a un sindicato. La fortaleza de la FOM en estos años era tal que quedó claro en la cantidad de agremiados cotizantes, que pasó de 6.000, en 1914, a 119.729, en 1919 (Caruso, 2016).

Como no podía ser de otra manera en esta coyuntura, los conflictos ferroviarios también reconocen una de sus principales causas en los efectos económicos de la guerra. Las empresas ferroviarias sufrieron una fuerte reducción en la recaudación y una caída de los márgenes de ganancia, como consecuencia de la contracción de las exportaciones y del aumento de los costos (por ejemplo, el carbón aumentó de nueve pesos oro la tonelada, en 1913, a treinta, en 1918). La solución temporal por parte de las compañías fue bajar los costos y la variable de ajuste, como ocurrió en casi todos los sectores económicos, lo que recayó en la baja de los salarios y la reducción de personal (de 132.000 empleados, en 1913, a 112.000, cinco años después). Esta situación provocó un profundo malestar entre los trabajadores, que comenzaron, a veces espontáneamente, a protestar y a efectuar reclamos, que no se limitaron solo a los aumentos de salarios, sino también a la reducción de la jornada laboral, la mejora de las condiciones de trabajo, la implementación del escalafón de ascensos, la puesta en marcha de un plan de jubilaciones y la reincorporación de los despedidos en la huelga de maquinistas de 1912 (Suriano, 1991).

Ya a mediados de 1916 se podía percibir el malestar de los obreros del Ferrocarril Central Argentino (de capitales británicos) a raíz de la huelga de los trabajadores en rechazo a la decisión de la empresa de disminuir la jornada laboral y los salarios. Un año más tarde pararon los trabajadores de los talleres de Rosario y Pérez, del mismo ferrocarril, en demanda de la reincorporación de los obreros despedidos en el conflicto anterior. ${ }^{10}$ Simultáneamente, 
en protesta por la reducción salarial, entre junio y setiembre de 1917, volvieron a producirse una serie de huelgas en el Central Argentino, de características radicalizadas, con dirección anarquista en muchos casos, que culminaron en una huelga general durante el mes de agosto. Tanto la Fraternidad como la Federación Obrera Ferroviaria (FOF), que hasta aquí habían tenido poca incidencia en el conflicto, apoyaron la huelga, con el argumento de que "manteniendo altas las tarifas ferroviarias para los fletes y reduciendo el salario de sus empleados, las compañías ferroviarias estaban obligando al país a financiar el esfuerzo bélico de Gran Bretaña, ya que el grueso de sus ganancias iba a parar a manos del Gobierno británico, en calidad de 'impuesto de guerra'" (Rock, 1977: 152-153). Un mes más tarde estallaron otras huelgas en la provincia de Santa Fe, con apoyo de la FOF, que declaró la huelga general. A partir de ahíse produjo otra ola de conflictos turbulentos entre noviembre de 1917 y abril del año siguiente, también por demandas salariales y por la falta de cumplimiento de las empresas ferroviarias de las disposiciones del Poder Ejecutivo sobre condiciones laborales y obligaciones diversas de las compañías.

Hay otra dimensión subyacente en los conflictos ferroviarios, que muestra en toda su magnitud el peso político, pero también emocional, de la guerra en esta coyuntura. Se trata de una cuestión que ha explorado Silvana Palermo y que había estado ausente, o apenas visible, en la producción historiográfica sobre el conflicto social en Argentina. En primer lugar debe destacarse que las empresas ferroviarias, tanto inglesas como francesas, estaban involucradas de manera activa en el esfuerzo bélico y alentaron, y a veces presionaron, a sus trabajadores a apoyar la causa aliada. Todos los directivos de estas empresas eran ingleses o franceses y tanto sus empleados jerárquicos como los trabajadores eran en buena medida inmigrantes provenientes de países participantes en la contienda. De una u otra manera, estaban emocionalmente involucrados con los bandos en pugna en la guerra. Casi todos tenían familiares o amigos en los frentes de batalla, y muchos de ellos lloraban la pérdida de seres queridos. Aunque no fueron la mayoría, no deben de haber sido pocos los trabajadores que dejaron el país para marchar al frente de batalla. La adhesión a los bandos en pugna cruzó los conflictos que se produjeron entre los trabajadores y las empresas ferroviarias durante estos años. En este sentido, el hecho novedoso de esta coyuntura radica en que "la protesta laboral se imbricó con el enfrentamiento entre países y las solidaridades de clases sociales debieron construirse en competencia con las exaltadas lealtades nacionales" (Palermo, 2013: 4).

En el caso específico de la protesta ferroviaria las empresas francesas y británicas acusaban a los trabajadores de aliarse con el enemigo, al impedir que los alimentos llegaran normalmente a los ejércitos aliados. Apelando a los sentimientos patrióticos, los presionaron para que no hicieran huelgas. $Y$ en ese esfuerzo recurrieron incluso a teorías conspirativas. 
Por ejemplo, el cónsul británico en el país sostenía que en 1916 habían arribado al país anarquistas españoles con dinero del Gobierno alemán para organizar huelgas y entorpecer el envío de víveres a los aliados. Así, intentaba vincular a los huelguistas con el enemigo de guerra. ${ }^{11}$ Durante el año siguiente se generalizó la opinión empresarial, apoyada por algunos medios de prensa, de que los huelguistas eran apoyados por el capital alemán.

Los dirigentes sindicales percibieron la perturbación que significaba la injerencia de los sentimientos nacionales para la protesta laboral y para las solidaridades de una clase obrera atravesada por la diversidad de orígenes nacionales. El periódico La Fraternidad sostenía que en las compañías francesas instaban a los trabajadores connacionales "cualquiera sea su edad y número de familia, que concurran a la masacre del viejo mundo dejando abandonado sus hogares. Y a los que se rehúsan a partir, alegando muy justificadas razones, se les mortifica con castigos injustos y continuos". ${ }^{12}$ Incluso hubo denuncias concretas $y$, no fueron pocas, de que el FC Pacífico estaba expulsando a obreros alemanes y austriacos por el solo hecho de haber nacido en los países enemigos.

Durante los conflictos las empresas no estuvieron solas. Recibieron en numerosas ocasiones el respaldo de asociaciones étnicas (italianas, francesas), queinstaban a los trabajadores a no realizar huelgas para no entorpecer los embarques de granos y carnes destinados al frente de batalla. ${ }^{13}$ La Guerra Mundial se había convertido en un nuevo elemento movilizador de las comunidades de inmigrantes y de los sentimientos patrióticos, que podían anteponerse, en esta coyuntura, a los intereses de los diversos sectores sociales de dichas comunidades.

Los efectos de la guerra también perturbaron la política laboral del Gobierno de Yrigoyen. No es este el lugar para analizar dichas políticas, pero cabe recordar que la llegada del primer Gobierno producto de la reforma electoral de 1912 tendió a aumentar el malestar de las elites. No se trataba solamente del rechazo al estilo popular del presidente Yrigoyen, sino de la profunda mutación que se produjo en las formas de resolver los conflictos inherentes a la relación entre el capital y el trabajo. El presidente comenzó a arbitrar personalmente en aquellas huelgas (de marítimos, ferroviarios) más importantes y que tendían a interrumpir el tránsito de personas y mercaderías y en varias ocasiones laudó favorablemente a los trabajadores. Lo que era una simple mediación fue objeto de durísimas críticas por parte de las elites, particularmente de los grandes empresarios, quienes catalogaron a Yrigoyen de "presidente obrerista", obviamente una apreciación exagerada y cargada de intencionalidad.

Durante los conflictos de 1917 y 1918 las empresas apelaron, por convicción o conveniencia, a la versión conspirativa e insistían en la existencia de agentes alemanes que podían actuar libremente debido a la permisividad del gobierno de Yrigoyen, al que tildaban de 
progermano. Era una forma de presionar directamente sobre un Gobierno que era acusado de haber intervenido favorablemente a los trabajadores en los conflictos e indirectamente sobre la postura de neutralidad ante la guerra, que había sido declarada por la gestión anterior, del conservador Victorino de la Plaza. Las posturas de las compañías ferroviarias frente a las huelgas eran apoyadas sin fisura por los grandes empresarios y por diarios como La Nación. Acuciado por la crisis, el Gobierno sentía la presión de los factores de poder económico y cada vez le costaba más mantener una posición neutral en las huelgas. Cuando en febrero de 1918 estalló una nueva huelga en los ferrocarriles "el diplomático británico Reginald Tower informó perentoriamente a las autoridades que si no cesaban las huelgas se dejarían sin efecto los convenios sobre la venta de cereales (a los aliados) y el Gobierno británico impondría un boicot a los puertos argentinos" (Rock, 1977: 161). Esta situación y las fuertes presiones de los factores de poder llevaron al Gobierno de Yrigoyen a endurecer su postura frente a los conflictos ferroviarios y, para terminar con ellos, apeló a la represión policial e incluso del ejército.

En este contexto aparecerían otros factores ligados de una u otra manera a la contienda europea, que alentarían la radicalización de los conflictos obreros patronales. El estallido de la Revolución Rusa había generado el entusiasmo de las vanguardias obreras de todo el mundo y la fe en la creencia de que el cambio social era ahora posible y dejaba de ser una lejana utopía. Este clima se irradió por todo el mundo y la Argentina no fue una excepción, al contrario, se imbricó con la oleada de conflictos sindicales, generando el entusiasmo de aquellas corrientes más radicalizadas, así como también profundizando las inquietudes existentes entre las elites, que contribuirían a crispar más los ánimos y a profundizar la percepción negativa que estas tenían del movimiento sindical, no importa que este no tuviera como meta la revolución social. Esta situación se agudizaría dramáticamente durante la huelga general de la Semana Trágica de enero de 1919, un conflicto que comenzó en una empresa metalúrgica con reclamos vinculados al deterioro del salario real producido durante la guerra y que terminaría convirtiéndose, debido a la brutal represión policial, en una formidable demostración de solidaridad obrera (Bilsky, 1984). La gravedad de la situación alentó la ola de rumores, interesados o no, sobre supuestos complots maximalistas, que desembocaron, con la complicidad de las autoridades, en la durísima contra movilización civil dedicada a reprimir todo atisbo de radicalidad obrera, pero que excedió este primer objetivo para transitar el sendero de un nacionalismo chauvinista y antisemita. Sin duda, detrás de este conflicto y de la ola de huelgas de estos años se escondía la preocupación por las consecuencias que podría acarrear la revolución rusa, que aparecía como una fuente de preocupaciones en la derecha del espectro político e intelectual argentino. Esta preocupación recorría las páginas 
del conservador diario La Nación, o de otras publicaciones a través de la "encuesta sobre el maximalismo" o en la "Encuesta sobre la cuestión social", realizada por la Revista de Ciencias Económicas en 1920. Como sostiene Robeto Pittaluga, "la revolución rusa actuaba al menos en dos planos; por un lado, abriendo un nuevo horizonte epocal, aun para quienes lo observaban recelosos, y por otro, inscribiendo sus nombres (soviets, maximalismo, etc.) en el léxico político local" (Pittaluga, 2016: 14-15). ${ }^{14}$

Esa preocupación adquiría ciertos rasgos esquizofrénicos entre los empresarios más poderosos: la ola de conflictos, la fuerza adquirida por las organizaciones sindicales, el mencionado impacto de la revolución rusa y la postura mediadora del Gobierno alentaron a las grandes empresas (Molinos, Mihanovich, Dodero, Molinos, los frigoríficos, las compañías ferroviarias extranjeras, entre otras) a crear una organización defensiva y ofensiva. Nucleados en la Bolsa de Comercio, fueron ellos los principales impulsores de la creación de la Asociación del Trabajo (AT), en mayo de 1918, con el objetivo central de preservar la "libertad de trabajo". La presentación la realizó un directivo del Centro de Navegación y miembro de la Bolsa de Comercio, como un proyecto para crear una "corporación con el especial objeto de defender los derechos e intereses de la industria y el comercio [y ratificar] el derecho de los comerciantes e industriales a elegir y despedir libremente a los empleados y obreros". ${ }^{15}$ La AT nucleó a los sectores empresariales más concentrados y poderosos (Bolsa de Comercio, Sociedad Rural, Centro de Exportadores de Cerales, Centro de Importadores, Centro de Navegación, Centro de Cabotaje, compañías ferroviarias, Cámara Gremial de Molineros, Centro de Barraqueros, Mercado Central de Frutos y la Compañía Italo-Argentina de Electricidad). La Unión Industrial Argentina, si bien no se incorporó, dio libertad a sus afiliados para elegir si adherir o no a la nueva organización.

Debido a la capacidad de organización y de protesta adquirida por el gremio marítimo, no fue una casualidad que el principal promotor de la AT fuera el Centro de Navegación, que también había sido el impulsor, unos años antes, de la Sociedad Protectora del Trabajo Libre, que se encargaba de proveer rompehuelgas a las empresas que lo requiriesen. La AT se convirtió en una activa protagonista, "una supra-organización corporativa [que] buscaría superar el marco de las organizaciones sectoriales para intentar conformar una fuerza patronal homogénea, que actuara como articuladora social y política" con el objeto de combatir las "exigencias desmedidas e injustas" de los sindicatos y al Gobierno de Yrigoyen, que no ofrecía garantías para contrarrestar a las organizaciones obreras (Rapalo, 2012: 99). La AT aumentó su gravitación a partir de enero de 1919, cuando disputó el control del puerto a la FOM. También fue una de las artífices, ese mismo año, de la creación de la Liga Patriótica. Compartió "la creación de un 'cuerpo de policía' o de guardias armados dispuestos a quebrantar al 
movimiento obrero" (Rapalo, 2012: 163-164). Realizaron una fuerte presión sobre el Gobierno radical, para que este garantizara la libertad de trabajo a través de lockouts, apelaron a la presión internacional, a los legisladores adictos y a la prensa. Finalmente lograron doblarle el brazo al Gobierno, cuando, en mayo de 1921, el presidente Yrigoyen reintegró la presencia de la prefectura en el puerto de Buenos Aires, al romper el acuerdo con la FOM y quebrar su resistencia. También realizaron una activa campaña en oposición a las iniciativas sobre legislación laboral.

La historia global se vincula a dos sentidos muy definidos. Por un lado, aborda procesos históricos que tienden a desarrollar la integración de países (mundialización); por otro, se refiere a una perspectiva metodológica apoyada en el desplazamiento del foco de análisis desde el Estado Nación a un contexto más amplio, que implica precisamente la internacionalización de esos espacios nacionales (Douki y Minard, 2007: 7-21). En este sentido, este artículo no es estrictamente un trabajo de historia global, pero bajo su inspiración he abordado el devenir del mundo del trabajo en una coyuntura dominada por los efectos provocados por la Primera Guerra Mundial, un evento excepcional que desnudó en todas sus dimensiones las formas de interpenetración que había adquirido la economía mundial. Una interconexión que claramente excedía los deseos de los Estados Nación latinoamericanos y que revelaba la extrema dependencia de las economías locales con respecto a los factores internacionales. Aun cuando la vieja historia universal ya había prestado atención a esta problemática, fue escasamente tenida en cuenta mientras se mantuvo el predominio de historias nacionales, que tendieron a homogeneizar las unidades nacionales. Tal vez los contemporáneos tuvieran (y tienen), como ha sostenido Roger Chartier, una "conciencia de globalidad", que comanda, a su manera, la de los historiadores. Razón por la cual "en el Congreso de Oslo Natalie Davis propuso, como una práctica posible de la historia universal, una historia que, sin renunciar a sus objetos o a sus escalas clásicas, se inspire de una conciencia global" (Chartier, 2001:122). En el caso de este artículo, conciencia global implica pensar el mundo del trabajo argentino teniendo en consideración que su devenir está íntimamente relacionado con el proceso de integración de países en el plano internacional, pero prestando atención a las peculiaridades del mundo del trabajo construido en el interior de los marcos del Estado Nación argentino. En todo caso, para construir una historia global vinculada al mundo del trabajo es necesario no solo abordarla desde una escala mundial, sino uniendo cada una delas piezas que integran ese mundo global. 


\section{NOTAS}

1 Alrededor de 10 millones de víctimas fatales y 20 millones de heridos.

2 La historiografía argentina ha prestado escasa atención a los diversos efectos que la Guerra tuvo en el mundo del trabajo. No me refiero solo a las consecuencias negativas, desde el punto de vista económico, sobre las condiciones de vida de los trabajadores, sino también, teniendo en cuenta que la mayoría de ellos provenían de Europa, a las posturas sustentadas por estos y por sus representaciones políticas e ideológicas sobre el conflicto. Sobre la producción historiográfica argentina en torno a la guerra, véase Tato (2014: 91-101).

3 "La decisión del Banco de Inglaterra de incrementar la tasa de interés provocó la reversión del flujo de capitales extranjeros hacia el país, poniendo en evidencia su profunda depresión en materia financiera" (Belini y Korol, 2012: 25-26).

4 Declaración del primer congreso de la CORA, 27 y 28 de junio de 1914, en Marotta (1961: Tomo II, 162).

5 Recién a partir de 1919-1920 se recuperó el flujo de inmigrantes, aunque no en los volúmenes anteriores a la guerra.

6 Revista de Economía Argentina, octubre de 1919, p. 309.

7 Crónica Mensual del Departamento Nacional del Trabajo (CMDNT), № 10, octubre de 1918, pp. 159 y 160.

8 CMDNT, no 19, julio de 1919, pp. 290 a 293.

9 El Día, 14 de mayo de 1915. En Lobato (2001: 160).

10 CMDNT, ำ 2, p. 17

11 Rock (1977: 322) sostiene que fue una invención análoga a la de los agentes rusos durante la Semana Trágica, en 1919.

12 La Fraternidad, octubre de 1916 en Palermo (2013: 12).

13 Sobre la actitud de algunas de las colectividades extranjeras radicadas en Argentina cuyos países se habían involucrado en la guerra, véase Devoto (2006: 318-327); Franzina (2000); Otero (2009).

14 Roberto Pittaluga (2016: 14-15).

15 La Nación, 23 de mayo de 1918, en Rapalo (2012: 96).

\section{REFERENCIAS BIBLIOGRÂFICAS}

BELINI, Claudio y KOROL, Juan Carlos. Historia económica de la Argentina en el siglo XX. Buenos Aires: Siglo Veintiuno, 2012.

BILSKY, Edgardo. La semana trágica. Buenos Aires: CEAL, 1984.

BUNGE, Alejandro. La desocupación en la Argentina. La actual crisis del trabajo, Estudios, Buenos Aires, 1917.

CARUSO, Laura. Embarcados. Los trabajadores marítimos y la vida a bordo: sindicatos, empresas y Estado en el puerto de Buenos Aires, 1889-1921. Buenos Aires: Imago Mundi, 2016. 
CHARTIER, Roger. "La conscience de la globalité (commentaire)", Annales. Histoire, Sciences Sociales, 1, enero-febrero de 2001.

COMPAGNON, Olivier. Entrer en guerre? Neutralité et engagement de l'Amérique latine entre 1914 et 1918, Relations Internationales, 137, 2009, pp. 31-43.

_. L'adieu à I'Europe. L'Amerique Latine et la Grande Guerre. Paris: Fayard, 2013.

DEVOTO, Fernando. Historia de los italianos en la Argentina. Buenos Aires: Biblos, 2006.

DI TELLA, Guido y ZYMELMAN, Manuel. Las etapas del desarrollo argentino. Buenos Aires: Eudeba, 1967.

DORFMAN, Adolfo. Historia de la industria argentina. Buenos Aires: Solar/Hachette, 1970.

DOUKI, Caroline y MINARD, Philippe. Histoire globale, histories conectées: un changement d'échelle historiographique?, Revue D'Histoire Moderne et Contemporaine, ㄲo 54-4 bis, 2007.

FRANZINA, Emilio. La guerra lontana: il primo conflitto mondiale e gli italiani d'Argentina, Estudios Migratorios Latinoamericanos, vol. 15, ㄲo 44, 2000.

HOBSBAWM, Eric. Historia del siglo XX. Barcelona: Crítica, 1995.

LOBATO, Mirta Zaida. La vida en las fábricas. Trabajo, protesta y politica en una comunidad obrera, Berisso (1904-1970). Buenos Aires: Prometeo, 2001.

y SURIANO, Juan. Atlas Histórico. Buenos Aires: Sudamericana, 2000.

MAROTTA, Sebastián. El movimiento sindical argentino. Su génesis y desarrollo. Buenos Aires: Ediciones Lacio, 1961.

OTERO, Hernán. La guerra en la sangre. Los franco-argentinos ante la Primera Guerra Mundial. Buenos Aires: Sudamericana, 2009.

PALERMO, Silvana. Protesta y cultura popular desde una perspectiva global: la huelga ferroviaria de 1917 en Argentina en tiempos de la Gran Guerra. Ponencia presentada en Coloquio Internacional: Latinoamérica y la Historia Global, Universidad de San Andrés, Buenos Aires, 2013.

PITTALUGA, Roberto. La izquierda de la Argentina frente la revolución en Rusia. Buenos Aires: Prometeo, 2016.

RAPALO, María Ester. Patrones y obreros. La ofensiva de la clase propietaria. Buenos Aires: Siglo Veintiuno, 2012.

ROCK, David. El radicalismo argentino, 1890-1930. Buenos Aires: Amorrortu editores, 1977.

SANTILLÄN, Diego Abad de. La F.O.R.A. Ideología y trayectoria. Buenos Aires: Editorial Proyección, 1971.

STEVENSON, David, 1914-1918 Historia de la Primera Guerra Mundial. Barcelona: Penguin-Randon House, 2013.

SURIANO, Juan. Estado y conflicto social: el caso de la huelga de maquinistas ferroviarios de 1912, Boletín No. 4, Instituto de Historia Argentina y Americana Dr. Emilio Ravignani, Buenos Aires, 1991.

TATO, María Inés. La Gran Guerra en la historiografía argentina. Balance y perspectiva de investigación, Iberoamericana, vol. XIV, no 53, 2014. 